\title{
Combinatorial Enzyme Approach for Production and Screening of Libraries of Feruloyl Oligosaccharides
}

\author{
Dominic W. S. Wong*, Sarah Batt, William Orts \\ Western Regional Research Center, USDA-ARS, Albany, CA, USA \\ Email: *Dominic.Wong@ars.usda.gov
}

How to cite this paper: Wong, D.W.S., Batt, S. and Orts, W. (2020) Combinatorial Enzyme Approach for Production and Screening of Libraries of Feruloyl Oligosaccharides. Advances in Enzyme Research, 8, 27-37.

https://doi.org/10.4236/aer.2020.83003

Received: September 2, 2020

Accepted: September 27, 2020

Published: September 30, 2020

Copyright $\odot 2020$ by author(s) and Scientific Research Publishing Inc. This work is licensed under the Creative Commons Attribution International License (CC BY 4.0).

http://creativecommons.org/licenses/by/4.0/

\begin{abstract}
Combinatorial chemistry involves the chemical or biological synthesis of diverse variation of the structures of a target molecule and the library is then screened for variants of desirable target properties. The approach has been a focus of research activity in drug discovery and biotechnology. This report is to demonstrate the application of enzyme technology using the concept of combinatorial chemistry as a novel approach for the bioconversion of plant fibers. Wheat insoluble fiber was subjected to combinatorial enzyme digestion to create structural variants of feruloyl oligosaccharides (FOS). Fractionation and screening resulted in the isolation of a fraction of bioactive FOS species showing antimicrobial activity. These results demonstrate the feasibility and usefulness of the combinatorial enzyme technique in the transformation of plant biomass to value-added products.
\end{abstract}

\section{Keywords}

Combinatorial Enzyme, Wheat Insoluble Arabinoxylan, Feruloyl

Oligosaccharides, Endo-Xylanase, $\alpha$-L-Arabinoxylanosidase

\section{Introduction}

Combinatorial chemistry involves the synthesis of a large array of diverse structural variations of the molecule of interest and the constructed library is then screened for target variants exhibiting desirable activities and functions [1] [2] [3]. A simple organic molecule with a core structure carrying 3 scaffolds, each randomly comprised of 4 types of substituents would result in a combinatorial library of $4^{3}=64$ structural variants. A hexapeptide library randomized with the 20 natural amino acids at each position would produce a population of $20^{6}=64$ 
million distinct peptides. Chemical techniques used for creating combinatorial libraries involve solid-phase synthesis and its refinements for libraries of small organic molecules, peptides, and oligonucleotides. In contrast, the biological approach uses the genetic code as a precursor to express randomized libraries in microorganisms, such as phage, E. coli, and yeast, through systematic and repetitive selection, mutation and amplification. The recent development of dynamic combinatorial chemistry enables the design of "smart" materials libraries of molecules evolved under thermodynamic control by responding and re-equilibrating to external conditions [4].

Numerous reviews have discussed the technology and application of combinatorial chemistry for drug discovery and optimization [3] [5]. Receiving much less attention is the potential use of combinatorial chemistry concept in agrosciences [6], and in agriculture and food research [1] [2]. Plant cell wall polysaccharides, such as xylan, pectin, and xyloglucan, consist of polymeric backbones decorated with various side groups that are cleavage targets of specific enzymes. The presence of these side groups as well as their positions, density, and types of linkages further influence the pattern of enzymatic degradation of the main chain polymer and vice versa. Alteration of the degradation pattern of the modified main chain would in turn lead to hydrolytic products of diverse structures. Enzymatic removal of the side group moieties individually and/or sequentially, therefore, constitutes a combinatorial design. The structural variation expressed in the oligosaccharide products, will translate into changing reactivity and functional properties. Figure 1 presents schematically a few examples of potential oligosaccharide structures from enzymatic digestion of plant fibers.

The hemicellulose polymer xylan contains a $\beta$-1,4-xylosyl main chain decorated with at least four types of side groups viz acetyl groups, phenolic-ferulic acids, glucuronyl residues, and arabinofuranosyl residues [7]. The cleavage of these side groups requires acetylxylan esterase, feruloyl esterase, $\beta$-glucuronidase, $\alpha$ - $L$-arabinofuranosidase, respectively. These side groups can be removed in a combinatorial scheme by specific enzymes targeting each group individually or in various combinations under different reaction conditions. The present work

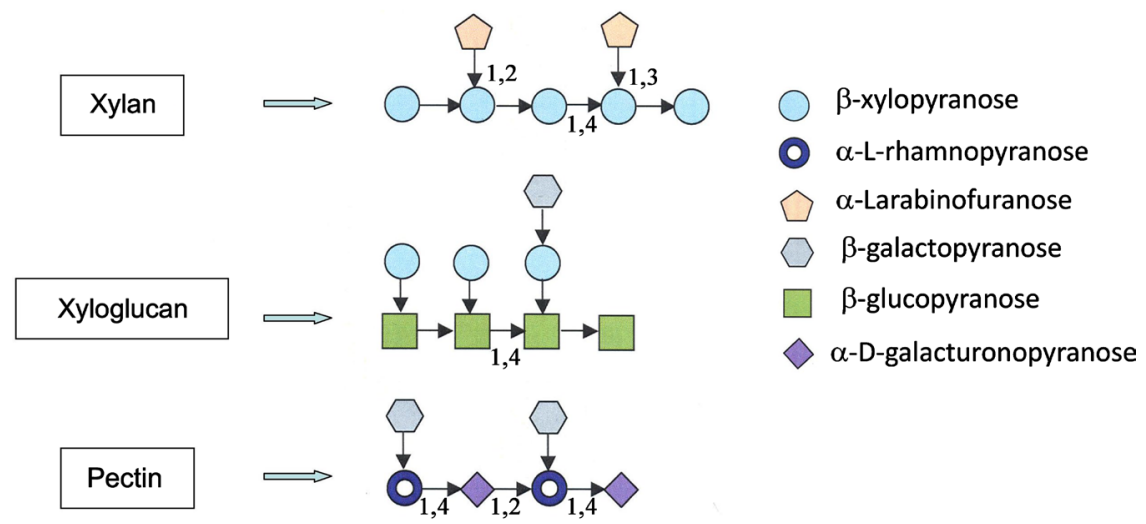

Figure 1. Schematic illustration of some examples of potential oligosaccharide structures from controlled enzymatic hydrolysis of plant fibers. 
describes combinatorial enzyme digestion of wheat insoluble arabinoxylan to produce libraries of xylo-oligosaccharides, resulting in isolation of FOS species exhibiting specific functional activities.

\section{Materials and Methods}

\section{Materials}

Wheat insoluble arabinoxylan (WIA), Aspergillus niger $\alpha$ - $L$-arabinofuranosidase (AnABF), Bifidobacterium adolescentis $\alpha$ - $L$-arabinofuranosidase (BaABF), and Thermotoga maritima $\beta$ - $D$-xylanase (GH10) (TmXYN) were purchased from Megazyme (Wicklow, Ireland). E. coli (ATCC 8739) was obtained from American Type Culture Collection (Manassas, VA). Mueller Hinton (MH) broth and Amberlite XAD-2 were obtained from Sigma (St. Louis, MO). Sephadex LH20 was purchased from GE Healthcare (Pittsburg, PA). HPTLC plates were purchased from Analtech (Newark, DE). All chemicals and solvents were of analytical or HPLC grade. Distilled, Milli-Q water was used in all experiments.

\section{Enzymatic hydrolysis of wheat insoluble arabinoxylan}

WIA (100 g) was suspended by vortexing in $10 \mathrm{ml}$ water and soaked for 30 min at room temperature. AnABF and/or BaABF of varying nmole concentrations were added to the suspended substrate and mixed well by brief vortexing, followed by the addition of TmXYN at various concentrations. The mixture was incubated at $40^{\circ} \mathrm{C}$ for $24 \mathrm{hr}$ with shaking, and centrifuged at $4225 \mathrm{RCF}$ for 40 $\mathrm{min}$. The supernatant recovered was heated at $100^{\circ} \mathrm{C}$ for $10 \mathrm{~min}$ to inactivate the enzymes and filter sterilized (Nalgene rapid flow filter unit).

\section{Hydrophobic-interaction chromatography}

The enzyme hydrolysate was fractionated at room temperature using an Amberlite XAD-2 column $(2.5 \times 50 \mathrm{~cm})$. The enzyme digest was first eluted with $470 \mathrm{ml} \mathrm{H} \mathrm{H}_{2} \mathrm{O}$ at a flow rate of $0.7 \mathrm{ml} / \mathrm{min}$. Fractions of $12 \mathrm{ml}$ were collected. After washing with $\mathrm{H}_{2} \mathrm{O}, 800 \mathrm{ml}$ of $\mathrm{CH}_{3} \mathrm{OH} / \mathrm{H}_{2} \mathrm{O}(1: 1 \mathrm{v} / \mathrm{v})$ was used to elute the adsorbed FOS from the column. The fractions were measured for ferulic acids by $\mathrm{A}_{320}$ reading, for reducing sugars by the DNSA method [8], and for total carbohydrates by the phenol-sulfuric acid method [9] [10]. Fractions were pooled, concentrated by rotary evaporator, and reconstituted in $\mathrm{H}_{2} \mathrm{O}$ or suitable solvent.

\section{Size-exclusion chromatography}

The pooled fractions of FOS were dissolved in $\mathrm{CH}_{3} \mathrm{OH} / \mathrm{H}_{2} \mathrm{O}(1: 3 \mathrm{v} / \mathrm{v})$, and further purified using a Sephadex LH20 column $(2.5 \times 70 \mathrm{~cm})$. Separation was performed with $1: 3 \mathrm{CH}_{3} \mathrm{OH} / \mathrm{H}_{2} \mathrm{O}$ as eluant at a flow rate of $0.6 \mathrm{ml} / \mathrm{min}$. Fractions of $12 \mathrm{ml}$ were collected with absorbance measured at $320 \mathrm{~nm}$. Individual peaks were concentrated for further analysis of ferulic acids by HPLC and carbohydrate content as xylose equivalent by the phenol-sulfuric acid method as described below.

\section{Measurement of xylose equivalent and ferulic acid content}

The ferulic acid content in the concentrated samples was quantified by HPLC after alkaline hydrolysis $\left(1 \mathrm{~N} \mathrm{NaOH}, 37^{\circ} \mathrm{C}, 16 \mathrm{hr}\right)$ [11]. The carbohydrate con- 
centration as xylose equivalent was determined by the phenol-sulfuric acid method based on a xylose standard curve [9] [10].

\section{HPLC analysis}

HPLC analysis was performed on a Shimadzu LC-10 AD system fitted with a UV and RI detectors connected in tandem, using an oligosaccharide column (Supelcogel $\mathrm{Ag}+)(4.6 \times 250 \mathrm{~mm})$ with $\mathrm{H}_{2} \mathrm{O}$ as the mobile phase at a flow rate of $0.3 \mathrm{ml} / \mathrm{min}$ at $85^{\circ} \mathrm{C}$. Gel permeation chromatography (GPC) was performed using an Ultrahydrogel column $(7.8 \times 300 \mathrm{~mm})$, with water as the mobile phase at a flow rate of $0.3 \mathrm{ml} / \mathrm{min}$. Pullulan standards were used for molecular weight calibration. Analysis of ferulic acid concentration was performed on a Gilson system with a UV detector, using a Brownlee analytical C18 $5 \mu$ ODS column $(260 \times 4.6$ $\mathrm{mm}$ ), with $\mathrm{H}_{2} \mathrm{O} / \mathrm{HCOOH} / \mathrm{CH}_{3} \mathrm{CN}$ 7:1:2 mobile phase at a flow rate of $0.2 \mathrm{ml} / \mathrm{min}$.

\section{High-performance thin-layer chromatography}

The oligo samples were applied to a $20 \times 10 \mathrm{~cm}$ HPTLC silica gel F254 plate and developed with EtOAc/HOAc/ $\mathrm{H}_{2} \mathrm{O}$ (2:2:1). The plate was then sprayed with $10 \% \mathrm{H}_{2} \mathrm{SO}_{4}$ in methanol containing $1 \mathrm{mg} / \mathrm{ml}$ orcinol, followed by heating at $90^{\circ} \mathrm{C}$ for visualization of oligosaccharides.

\section{Growth experiments and culture conditions}

A freeze-dried E. coli (ATCC 8739) was rehydrated with $1 \mathrm{ml}$ sterile Difco ${ }^{\text {tu }}$ MH (Mueller Hinton) broth and streaked onto a $\mathrm{MH}$ agar plate. A $5 \mathrm{ml}$ culture $\left(35^{\circ} \mathrm{C}, 210 \mathrm{rpm}, 4 \mathrm{hr}\right)$ was prepared and the absorbance at $600 \mathrm{~nm}$ was measured. The culture was diluted with $\mathrm{MH}$ broth to a final concentration of $1 \times 10^{3}$ $\mathrm{cfu} / \mathrm{ml}$ based on a standard curve. The standard curve was constructed by plotting the number of colonies (by plate count) vs OD600 (liquid culture). The active FOS species (filter sterilized) was added to the diluted E. coli culture at various concentrations. Incubation was conducted at $35^{\circ} \mathrm{C}, 210 \mathrm{rpm}$ for various time periods. Cell growth was determined by measuring the absorbance at 600 $\mathrm{nm}$ of appropriate dilutions of the cell culture (SpectraMax M2, Molecular Devices, CA) and confirmed by plate counts. The oligo concentration as xylose equivalent was determined by the phenol-sulfuric acid method based on xylose standard curve. Minimum inhibitory concentration (MIC) is defined as the lowest concentration of an antimicrobial that inhibits the visible growth of a microorganism after overnight incubation [12] [13].

\section{Results and Discussion}

Feruloyl oligosaccharides have been studied using various degradation methods, including acid hydrolysis, hydrothermal processing, microwave-assisted autohydrolysis, and enzyme treatment of plant fibers such as corn and wheat bran, sugar-beet pulp, and insoluble wheat arabinoxylan [14] [15] [16] [17]. Most of these methods involved non-specific hydrolytic breakdown of the fiber and risked the uncontrolled formation of side products. Enzyme treatments are mostly restricted to the use of endo-xylanases, producing oligosaccharide products of limited structural variations. The present work employs a combinatorial 
concept utilizing the interactive effects of three enzymes viz Thermotoga maritima $\beta$ - $D$-xylanase (TmXYN), Aspergillus niger $\alpha$ - $L$-arabinofuranosidase (AnABF), and Bifidobacterium adolescentis $\alpha$ - $L$-arabinofuranosidase (BaABF). The T. maritima xylanase is a GH10 family xylanase which has an active site that can accommodate xylose residues decorated with side chains, producing small size oligosaccharide products, in contrast to GH11 xylanases that show preference for unsubstituted regions in the xylan backbone [18]. The two $\alpha$ - $L$-arabinofuranosidases $A n A B F$ and $B a A B F$ are members of specific classes of ABF-m and ABF-d3, respectively. ABF-m removes mono-substituted arabinofuranosyl (Araf) residues from arabinoxylans, whereas ABF-d3 removes the $O-3$ Araf from $O-2,3$-disubsituted $\mathrm{Xyl} p$ in arabinoxylans [19]. The action of each of these enzymes interactively affects the cleavage patterns among each other and the final outcome of the products, resulting in an expanded diversity of structural variation [20].

The soluble supernatant obtained from combinatorial enzyme digestion of wheat insoluble arabinoxylan was fractionated to obtain ferulic acid-containing oligosaccharides (FOS) (Figure 2). In contrast to the other fractions, the FOS fractions consisted of phenolic acid moieties as indicated by absorbance at 320 $\mathrm{nm}$. From the elution pattern, the FOS fractions were relatively more hydrophobic than the rest. The FOS yield (fractions 37 - 46) was about 10 - 13 percent based on xylose-equivalent, containing $98 \%$ of the ferulic acid content in the WIA digest. The ratio of xylose:FA was in the range of $\sim 55: 1$ based on the xylose equivalent (by the phenol-sulfuric acid method) and FA content (by HPLC analysis of alkaline hydrolyzed sample) as described in the "Methods" section. The FOS was applied to a Sephadex LH20 column, which further separated into

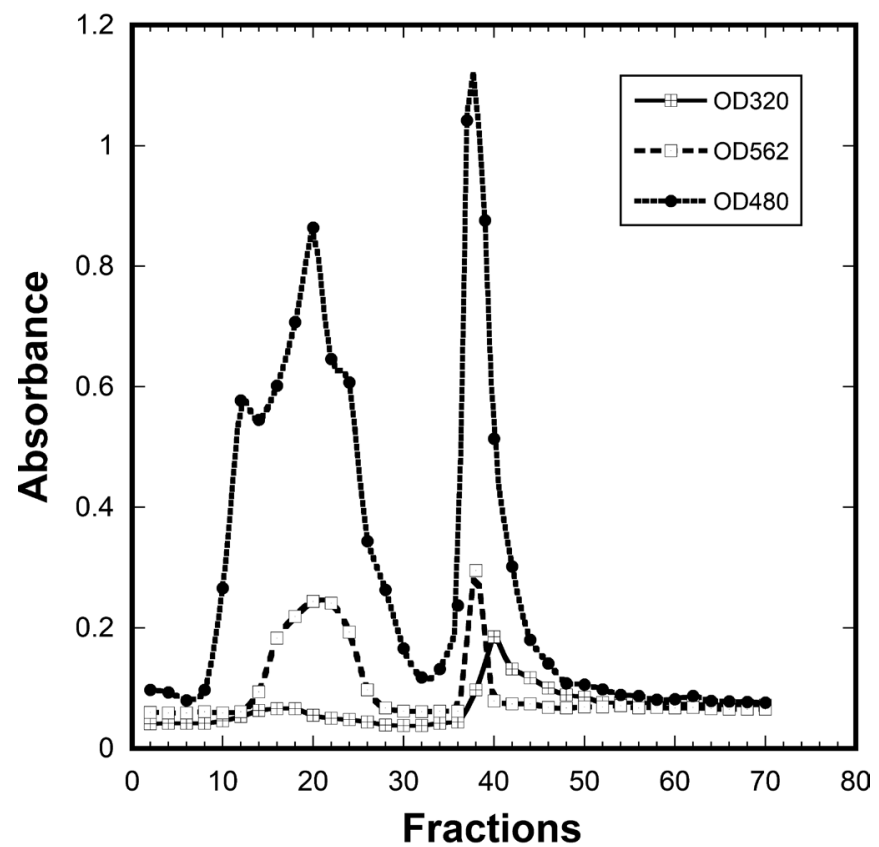

Figure 2. Hydrophobic chromatographic fractionation of enzyme-digested WIA. Column: $2.5 \times 50 \mathrm{~cm}$, Amberlite XAD-2; Flow rate: $0.7 \mathrm{ml} / \mathrm{min}$; Stepwise elution: $450 \mathrm{H}_{2} \mathrm{O}$, $800 \mathrm{ml} \mathrm{CH}{ }_{3} \mathrm{OH} / \mathrm{H}_{2} \mathrm{O}(1: 1 \mathrm{v} / \mathrm{v})$, Fractions collected: $12 \mathrm{ml} /$ tube. 
a major peak showing absorbance at $320 \mathrm{~nm}$ (indicating phenolic acids) and positive with the phenol- $\mathrm{H}_{2} \mathrm{SO}_{4}$ assay (suggesting carbohydrate neutral sugars).

The FOS showed an inhibitory effect on the growth of the E. coli strain ATCC 8379 in an initial testing. The enzyme-derived FOS was screened with the test microorganism E. coli ATCC 8379 for bioactive properties. In each set of experiments, the initial inoculation of the microorganism was carefully controlled to $1 \times 10^{3} \mathrm{cfu} / \mathrm{ml}$ titer, so that the comparisons were performed under same starting conditions. Figure 3(a) shows that the inhibitory effect increased with the concentration, and a complete suppression of cell growth was achieved at $0.07 \%$ $\mathrm{w} / \mathrm{v}$, which was the MIC (minimum inhibitory concentration) value. The antimicrobial effect was sustainable for three days and possibly longer (Figure 3(b)).

The FOS major peak from the LH20 column was analyzed by HPLC gel permeation chromatography showing a peak of $\mathrm{MW} \simeq 1.3 \mathrm{kD}$ (based on a pullulan standard curve) (Figure 4). This size range is generally considered in the category of low molecular weight oligosaccharides. The small size of the oligosaccharide may be a factor in facilitating its passage through the cell membrane. Reports of antimicrobial oligosaccharides generally refer to low molecular weight molecules, consisting of tri-, tetra-, and pentamers. Oligosaccharides in the high molecular weight range have been shown to prevent efficient in vivo utilization and generally are not effective in functional and biological activities [21] [22]. The present results seem to support the suggestion that small molecular
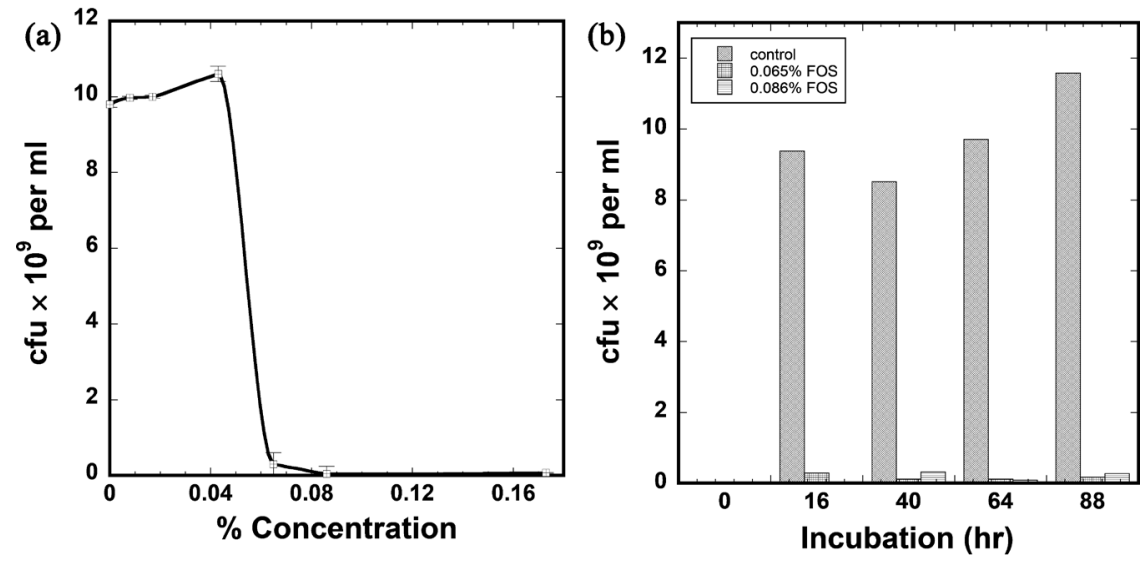

Figure 3. (a) Effect of the active FOS on cell growth. An overnight culture of $E$. coli (ATCC 8739 ) in $\mathrm{MH}$ broth at $35^{\circ} \mathrm{C}$ was diluted to appropriate titer concentrations, and various concentrations of FOS $(0.008 \%$ to $0.17 \%)$ were added. The incubation was continued for $16 \mathrm{hr}$. Cell growth was determined by measuring $\mathrm{A}_{600}$ of appropriate dilutions of cell culture, and the cfu/ml density was calculated based on the conversion curve. (b) Time course effect of the active DOS on cell growth. An overnight culture of E. coli (ATCC 8739) in $\mathrm{MH}$ broth at $35^{\circ} \mathrm{C}$ was diluted to appropriate titer concentrations, and the FOS species at 0.065 and $0.086 \%$ was added. The incubation was continued for 4 days with sampling at 16, 40, 64 and $88 \mathrm{hr}$. Cell growth was determined by measuring $\mathrm{A}_{600}$ of appropriate dilutions of the cell culture, and the $\mathrm{cfu} / \mathrm{ml}$ cell density was calculated using conversion curve. All experiments were performed in duplicates. Vertical bars on the data points in the figure represent standard deviations. In some case where the s.d. is very small compared to the axis scale, the bars may not be clearly visible. 


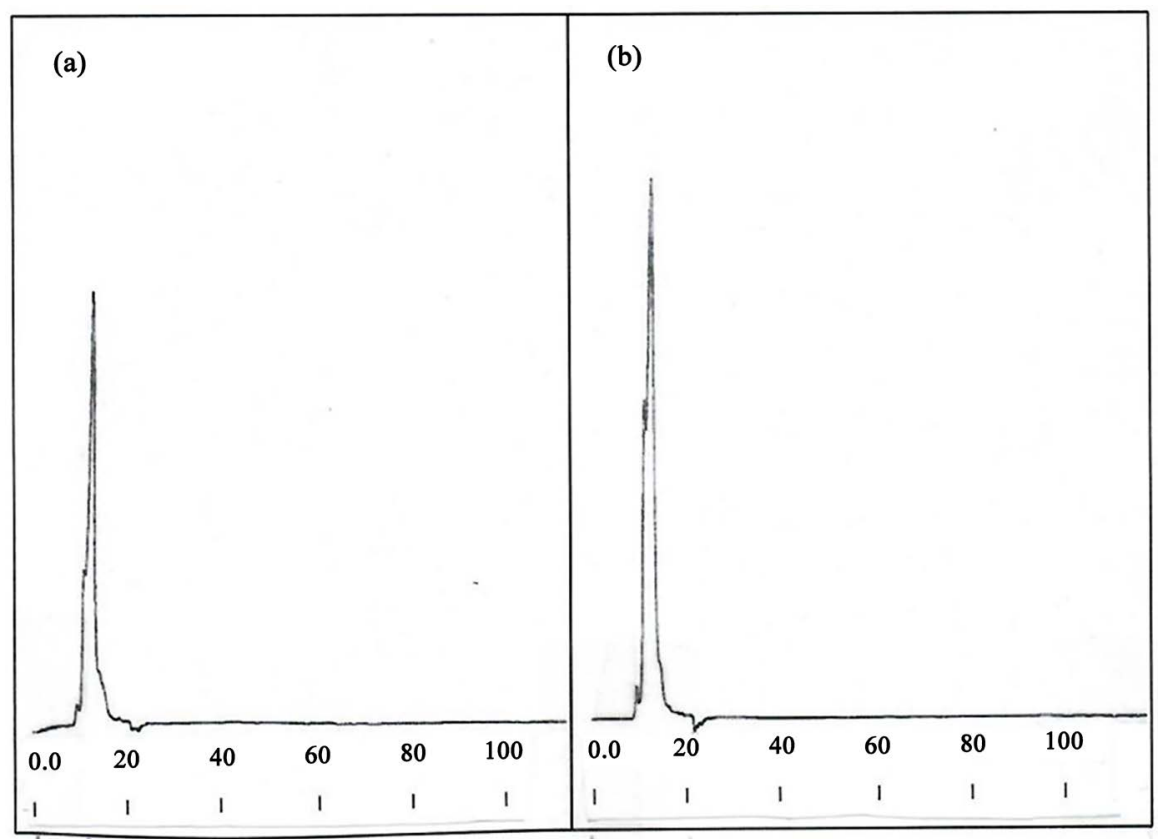

Figure 4. HPLC gel permeation chromatography of the active FA-oligo species. Analysis was performed on a Shimadzu LC-10 AD system fitted with UV-Vis and RI detectors connected in tandem, using a Ultrahydrogel 120 column (Waters, $4.6 \times 250 \mathrm{~mm}$ ). The mobile phase was $\mathrm{H}_{2} \mathrm{O}$ run at a flow rate of $0.3 \mathrm{ml} / \mathrm{min}$ at room temperature. (a) RI and (b) UV-vis $315 \mathrm{~nm}$ detection.

size may assist in the adhesion and penetration of the cell membrane, and increase potential interactions with intracellular constituents and processes. It is noted that the major peak on HPLC may not necessarily represent a single structure, but possibly a mixture of oligo species with similar sizes reflecting the same exclusion pattern on the gel matrix.

The mechanism of inhibition may be linked to the unique structural properties of the active species. The antimicrobial activity of some classes of phenolic compounds has been attributed to the presence of reactive double bonds and the association of the acid moiety [23]. Double bonds are electrophilic and can participate in a variety of reactions, resulting in crosslinking and inactivation of biomolecules. Antimicrobial activities of phenolic compounds are found in hydrolysis of lignocellulosic materials, comparable to the common preservative sodium benzoate [24]. Feruloyl oligosaccharides derived from feruloyl polysaccharides have been shown to have biological activities. A feruloylated arabinoxylan trisaccharide FAXX prepared from cell walls of bamboo shoots inhibits axin-stimulated cell growth of rice plants [25]. The study also indicates that the feruloyl substituent is necessary for the inhibitory effect, but the glycosyl portion of FAXX is also important for exerting full activity. Feruloyl oligosaccharides from corn bran and wheat aleurone have been shown to inhibit sucrase and maltase activities of $\alpha$-glucosidase and glucose absorption [26]. Wheat bran FOS has shown a higher antioxidant activity than free ferulic acid, and in vivo protection against oxidative stress in animal studies [27]. 
Other functional oligosaccharides have been reported in similar studies. Alginate oligosaccharides, consisting of guluronic and mannuronic acids in the main chain, have been reported to potentiate selected antibiotic actions against Candida and Aspergillus cell growth [28] [29]. Acidic (glucuronic acid-containing) xylo-oligosaccharides, particularly aldopentauronic acids, are effective inhibitors of certain gram-positive bacteria [21]. The pectic hydrolysate obtained by the digestion of citrus pectin with endo-polygalacturonase and pectate lyase resulted in active pectic oligo species with antimicrobial properties [30]. The mechanism of inhibition may be attributed to the unsaturated structure (reactive double bonds) due to the elimination reaction of pectate lyase, the acidic nature (carboxylic side groups) of the substituents, and the small size range of the molecule. Investigation will be necessary to characterize the structure and function connectivity as well as health cause-effects of functional oligosaccharides using molecular, biochemical, microbiological, and physiological studies.

The activity of FOS species in the present study can be considered comparable to those of some common food preservatives, which are generally applied in the range of $0.1 \%$. The use of non-digestible oligosaccharides (NDO) has become a thriving industry providing various prebiotics for food uses. Another potential use may be found in the animal feed industry. Functional oligosaccharides have been promoted as alternatives for antibiotics in animal production. These so-called natural antimicrobial growth promoters (AGP) have gained increasing attention in recent years [31]. The health cause-effect of these products is generally linked to the promotion of beneficial bacteria in the gut microbiome, and modification of the physiological environment of the intestinal digestive system [32]. In practical applications, functional oligosaccharides are used in sub-minimum inhibitor concentrations acting to modulate the microbiota composition.

\section{Conclusion}

Active FOS species has been derived from combinatorial enzyme digestion and isolated and shown to inhibit the growth of the E. coli test organism ATCC 8739. The MIC value was estimated to be comparable favorably to those reported for other active oligosaccharides and some common food preservatives. The FOS species may find useful application as a new source of high-value prebiotics or as alternatives to antimicrobial growth promoters.

\section{Acknowledgements}

Reference to a company and/or product is only for purposes of information and does not imply approval of recommendation of the product to the exclusion of others that may also be suitable. All programs and services of the U.S. Department of Agriculture are offered on a nondiscriminatory basis without regard to race, color, national origin, religion, sex, age, marital status, or handicap. The authors declare that there is no conflict of interest regarding the publication of this paper. 


\section{Conflicts of Interest}

The authors declare no conflicts of interest regarding the publication of this paper.

\section{References}

[1] Wong, D.W.S. and Robertson, D. (1999) Combinatorial Chemistry and Its Applications in Agriculture and Food. In: Shahidi, et al., Eds., Chemicals via Higher Plant Bioengineering, Kluwer Academic/Plenum Publishers, New York, 91-105. https://doi.org/10.1007/978-1-4615-4729-7_8

[2] Wong, D.W.S. and Robertson, G. (2004) Applying Combinatorial Chemistry and Biology to Food Research. Journal of Agricultural and Food Chemistry, 52, 7187-7198. https://doi.org/10.1021/jf040140i

[3] Kennedy, J.P., Williams, L., Bridges, T.M., Daniels, R.N., Weaver, D. and Lindsley, G.W. (2008) Application of Combinatorial Chemistry Science on Modern Drug Discovery. Journal of Combinatorial Chemistry, 10, 345-354. https://doi.org/10.1021/cc700187t

[4] Herrmann, A. (2014) Dynamic Combinatorial/Covalent Chemistry: A Tool to Read, Generate and Modulate the Bioactivity of Compounds and Compound Mixtures. Chemical Society Reviews, 43, 1899-1933. https://doi.org/10.1039/C3CS60336A

[5] Seneci, P., Fassina, G., Frecer, Y. and Miertus, S. (2014) The Effects of Combinatorial Chemistry and Technologies on Drug Discovery and Biotechnology-A Mini Review. Nova Biotechnologica et Chimica, 13, 87-108.

https://doi.org/10.1515/nbec-2015-0001

[6] Lindell, S.D., Pattenden, L.C. and Shannon, J. (2009) Combinatorial Chemistry in the Agrosciences. Bioorganic \& Medicinal Chemistry, 17, 4035-4046.

https://doi.org/10.1016/j.bmc.2009.03.027

[7] Biely, P., Singh, S. and Puchart, V. (2016) Towards Enzymatic Breakdown of Complex Plant Xylan Structure: State of the Art. Biotechnology Advances, 34, 1260-1274. https://doi.org/10.1016/j.biotechadv.2016.09.001

[8] Miller, G.L. (1959) Use of Dinitrosalicyclic Acid Reagent for Determination of Reducing Sugar. Analytical Chemistry, 31, 426-428.

https://doi.org/10.1021/ac60147a030

[9] Dubois, M., Gilles, K.A., Hamilton, J.K., Rebers, P.A. and Smith, F. (1956) Colorimetric Method for Determination of Sugars and Related Substances. Analytical Chemistry, 28, 350-356. https://doi.org/10.1021/ac60111a017

[10] Masuko, T., Minami, A., Iwasaki, N., Majima, T., Nishimura, S.-I. and Lee, Y.C. (2005) Carbohydrate Analysis by a Phenol-Sulfuric Acid Method in Microplate Format. Analytical Biochemistry, 239, 69-72.

https://doi.org/10.1016/j.ab.2004.12.001

[11] Bartolome, B., Faulds, B., Kroon, P.A., Waldron, K., Gilbert, H.J., Hazlewood, G. and Williamson, G. (1997) An Aspergillus niger Esterase (Ferulic Acid Esterase III) and a Recombinant Pseudomonas fluorescens subsp. Cellulose Esterase (XylD) Release a 5-5' Ferulic Dehydrodimer (Diferulic Acid) from Barley and Wheat Cell Walls. Applied and Environmental Microbiology, 63, 208-212. https://doi.org/10.1128/AEM.63.1.208-212.1997

[12] Nychas, G.J.E. (1995) Natural Antimicrobnials from Plants. In: Gould, G.W., Ed., New Methods of Foods Preservation, Blackie Academic/Chapman \& Hall, Glasgow, 53-83, 3-2, 87-108.

[13] Andrews, J.M. (2001) Determination of Minimum Inhibitory Concentrations. 
Journal of Antimicrobial Chemotherapy, 48, 5-16.

https://doi.org/10.1093/jac/48.suppl_1.5

[14] Saulnier, L., Vigouroux, J. and Thibault, J.-F. (1995) Isolation and Partial Characterization of Feruloylated Oligosaccharides from Maize Bran. Carbohydrate Research, 272, 241-253. https://doi.org/10.1016/0008-6215(95)00053-V

[15] Yuan, X., Wang, J. and Yao, H. (2006) Production of Feruloyl Oligosaccharides from Wheat Bran Insoluble Dietery Fibre by Xylanases from Bacillus subtilus. Food Chemistry, 95, 484-492. https://doi.org/10.1016/j.foodchem.2005.01.043

[16] Rose, D.J. and Inglett, G.E. (2010) Two-Stage Hydrothermal Processing of Wheat (Triticum acestivum) Bran for the Production of Feruloylated Arabinoxylooligosaccharides. Journal of Agricultural and Food Chemistry, 58, 6427-6432. https://doi.org/10.1021/jf100058v

[17] Ou, J. and Sun, Z. (2014) Feruloylated Oligosaccharides: Sturcture, Metabolism and Function. Journal of Functional Foods, 7, 90-100.

https://doi.org/10.1016/j.jff.2013.09.028

[18] Pollet, A., Delcour, J.A. and Courtin, C.M. (2010) Structural Determinants of the Substrate Specificities of Xylanases from Different Glycoside Hydrolase Families. Critical Reviews in Biotechnology, 30, 176-191. https://doi.org/10.3109/07388551003645599

[19] Koutaniemi, S. and Tenkanen, M. (2016) Action of Three GH51 and One GH54 $\alpha$-Arabinofuranosidases on Internally and Terminally Located Arabinofuranosyl Brnahces. Journal of Biotechnology, 229, 22-30.

https://doi.org/10.1016/j.jbiotec.2016.04.050

[20] van den Broek, L.A.M., Lloyd, R.M., Beldman, G., Verdoes, J.C., McCleary, B.C. and Voragen, A.G.J. (2005) Cloning and Characterization of Arbinoxylan Arabinofuranohydrolase-D3 (AXHd3) from Bifidobacterium adolescentis DSM20083. Applied Microbiology and Biotechnology, 67, 641-647. https://doi.org/10.1007/s00253-004-1850-9

[21] Christakopoulos, P., Katapodis, P., Kalogeris, E., Kekos, D., Macris, B.J., Stamatis, H. and Shaltsa, H. (2003) Antimicrobial Activity of Acidic Xylo-Oligosaccharides Produced by Family 10 and 11 Endoxylanases. International Journal of Biological Macromolecules, 31, 171-175. https://doi.org/10.1016/S0141-8130(02)00079-X

[22] Chaari, F., Belghith-Ferrdri, L., Zaouri-Ellouzi, S., Driss, D., Bilbech, M., Kallel, F., Bouaziz, F., Mehdi, Y., Ellouz-Chaabouni, S. and Ghorbel, R. (2016) Antibacterial and Antioxidant Properties of Mixed Linkage Beta-Oligosaccharides from Extracted-Glucan Hydrolysed by Penicillium occitanis $\mathrm{EG}_{\mathrm{L}}$ Lichenasde. Natural Product Research, 30, 1353-1359. https://doi.org/10.1080/14786419.2015.1056185

[23] Garrote, G., Cruz, J.M., Moure, A., Dominguez, H. and Parajo, J.C. (2004) Antioxidant Activity of Byproducts from the Hydrolytic Processing of Selected Lignocellulosic Materials. Trends in Food Science and Technology, 15, 191-200. https://doi.org/10.1016/j.tifs.2003.09.016

[24] Aziz, N.H., Farag, S.E., Mousa, L.A. and Abo-Zaid, M.A. (1998) Comparativce Antibacterial and Antifungal Effects of Some Phenolic Compounds. Microbios, 93, 43-54.

[25] Ishii, T. and Saka, H. (1992) Inhibition of Auxin-Stimulated Elongation of Cells in Rice Lamina Joints by a Feruloylated Arabinoxyl Trisaccharide. Plant and Cell Physiology, 33, 321-324. https://doi.org/10.1093/oxfordjournals.pcp.a078257

[26] Malunga, L.N., Eck, P. and Beta, T. (2016) Inhibition of Intestinal-Glucosidase and Glucoser Absorption by Feruloylated Arabinoxylan Mono- and Oligosaccharides 
from Corn Bran and Wheat Aleurone. Journal of Nutrition and Metabolism, 2016, e193532. https://doi.org/10.1155/2016/1932532

[27] Ou, S.Y., Jackson, G.M., Jiao, X., Chen, J., Wu, J.-Z. and Huang, X.-S. (2007) Protection against Oxidative Stree in Diabetic Rats by Wheat Bran Feruloyl Oligosaccharides. Journal of Agricultural and Food Chemistry, 55, 3191-3195.

https://doi.org/10.1021/jf063310v

[28] Khan, S., Tendervik, A., Sletta, H., Klinkenberg, G., Emanuel, C., Onseyen, E., Myrvold, R., Howe, R.A., Walsh, T.R., Hill, K.E. and Thomas, D.W. (2012) Overcoming Drug Resistance with Alginate Oligosaccharides Able to Potentiate the Action of Selected Antibiotics. Antimicrobial Agents Chemotherapy, 56, 5134-5141. https://doi.org/10.1128/AAC.00525-12

[29] Tendervik, A., Sletta, H., Klinkenberg, G., Emanuel, C., Powell, L.C., Pritchard, M.F., Khan, S., Craine, K.M., Onseyen, E., Rye, P.D., Wright, C., Thomas, D.W. and Hill, K.E. (2014) Alginate Oligosaccharides Inhibit Fungal Cell Growth and Potentiate the Activity of Antifungals against Candida and Aspergillus spp. PLOS ONE, 9 , e112518. https://doi.org/10.1371/journal.pone.0112518

[30] Wong, D.W.S., Feng, D., Batt, S. and Orts, W. (2018) Combinatorial Enzyme Approach to Produce Oligosaccharides of Diverse Structures for Functional Screen. Advances in Enzyme Regulation, 6, 11-20. https://doi.org/10.4236/aer.2018.62002

[31] Huyghebaert, G., Ducatelle, R. and Van Immerseel, F. (2011) An Update on Alternatives to Antimicrobial Growth Promoters for Broilers. The Veterinary Journal, 187, 182-188. https://doi.org/10.1016/j.tvjl.2010.03.003

[32] Mussatto, S.I. and Mancilha, I.M. (2007) Non-Digestible Oligosaccharides: A Review. Carbohydrate Polymers, 68, 587-597.

https://doi.org/10.1016/j.carbpol.2006.12.011 